There is circumstantial evidence to suggest that a repeated succession of menstrual cycles before the first pregnancy may even be harmful to the breast ${ }^{14}$; recent epidemiological evidence shows that the risk of breast cancer increases with time elapsed from menarche to first pregnancy. ${ }^{1516}$ Such considerations highlight the importance of a fuller understanding of the changes taking place in the breast during the normal menstrual cycle and after the use of oral contraceptives.

We thank those women who generously volunteered to take part in this study and are grateful to Dr C S Corker and Mr R Sharpe for statistical advice.

\section{References}

${ }^{1}$ McCance, R A, Luff, M C, and Widdowson, E E, Fournal of Hygiene, 1937, 37, 571.

${ }^{2}$ Royal College of General Practitioners, Report on Oral Contraceptives and Health. London, Pitman Medical, 1974.
3 Ingleby, H, Bulletin of the International Association of Medical Museums, $1949,29,87$.

${ }^{4}$ Reimann, S P, and Seabold, P S, American fournal of Cancer, 1933, 17, 34.

${ }^{5}$ Geschickter, C F, Diseases of the Breast. Philadelphia, Lippincott, 1945.

${ }^{6}$ Masters, W H, and Johnson, V E, Human Sexual Response. London, Churchill, 1966.

' Hytten, F E, British Medical fournal, 1954, 1, 912

${ }^{8}$ Dawson, E K, Edinburgh Medical fournal, 1934, 41, 653.

${ }^{9}$ Marshall, W A, and Tanner, J M, Archives of Disease in Childhood, 1969, 44, 291.

${ }^{10}$ Haagensen, C D, Diseases of the Breast. London, Saunders, 1956.

11 Ozzello, L, and Speer, F D, American Fourral of Pathology, 1958, 34 (5), 993.

12 Engel, S, Proceedings of the Royal Society of Medicine, 1947, 40, 899.

13 Speert, H, Contributions to Embryology, 1948, 32, 9.

${ }^{14}$ Short, R V, in Physiology and Genetics of Reproduction, part A, ed E M Coutinho and F Fuchs. New York, Plenum, 1974.

${ }^{15}$ MacMahon, B, Cole, P, and Brown, J, Fournal of the National Cancer Institute, 1973, 50, 21.

${ }^{16}$ Shapiro, S, et al, in Host Environment Interactions in the Etiology of Cancer in Man, ed R Doll and I Vodopija, p 169. Lyon, International Agency for Research on Cancer, 1973.

\title{
Histological evidence of carcinoma in a hepatic tumour associated with oral contraceptives
}

\author{
M DAVIS, B PORTMANN, M SEARLE, RALPH WRIGHT, ROGER WILLIAMS
}

British Medical fournal, 1975, 4, 496-498

\section{Summary}

A primary hepatic tumour occurred in a 21-year-old woman who had been taking oral contraceptives for two years; she was treated by partial hepatectomy. Part of the neoplasm showed features suggestive of focal nodular hyperplasia, while the remainder had the histological characteristics of a well-differentiated hepatocellular carcinoma. This is the first report of malignant transformation of a tumour in a patient taking oral contraceptives.

\section{Introduction}

Since 197225 cases of benign primary tumour of the liver have been described in women taking oral contraceptives. ${ }^{1-12} \mathrm{~A}$ particular feature of these neoplasms has been their extreme vascularity, and two-thirds of the patients have presented with haemoperitoneum from spontaneous rupture, which carries a mortality of $60 \%$. We describe here for the first time a further complication of this condition: malignant transformation of the tumour.

\section{Case report}

A 21-year-old woman was found on a routine blood check to be anaemic with a haemoglobin of $9.9 \mathrm{~g} / \mathrm{dl}$ and an erythrocyte sedimentation rate of $100 \mathrm{~mm}$ in one hour (Westergren). Her history was negative except for an attack of acute hepatitis some two years earlier, from which she had made a complete recovery, with return to normal liver function. Hepatitis B surface antigen ( $\mathrm{HBsAg}$ ) had never been found in her serum. She had been taking Volidan (megestrol acetate $4 \mathrm{mg}$, ethinyloestradiol $50 \mathrm{~kg}$ ) for contraception continuously for two years, since her recovery from hepatitis.

Physical examination showed, in addition to the anaemia, firm enlargement of the left lobe of the liver. Liver function tests gave abnormal results, with a serum bilirubin of $20 u \mathrm{~mol} / 1(1.2 \mathrm{mg}$ $100 \mathrm{ml}$ ) and alkaline phosphatase of $244 \mathrm{IU} / \mathrm{l}$. Other investigations, including estimations of immunoglobulins, $\alpha$-fetoprotein, and HBsAg, showed no abnormalities. Coagulation test results were normal except for a slightly prolonged partial thromboplastin time. A technetium liver scan showed a filling defect in the left lobe of the liver, and a selenium scan showed uptake in this area. Hepatic arteriography confirmed the presence of a highly vascular tumour in the left lobe, supplied by the middle and left hepatic arteries. At laparoscopy the left lobe of the liver was diffusely enlarged and somewhat purple.

The patient underwent left hepatectomy on 6 November 1974 and left hospital three weeks later after an uneventful postoperative course. She has since remained well, with no evidence of tumour on serial liver scans.

PATHOLOGICAL APPEARANCES OF RESECTED TUMOUR

The left hepatectomy specimen weighed $820 \mathrm{~g}$ and contained a well-circumscribed multilobular mass $14 \mathrm{~cm}$ in diameter. Some parts of the lobules were light brown, but most of the tumour was grey and more friable. The central part of the mass was occupied by partially calcified fibrous tissue, which radiated between the lobules. Patchy haemorrhages were scattered throughout the mass, but no major haemorrhage was seen.

Microscopic examination showed the whole tumour to be well demarcated from the surrounding liver tissue, which was histologically normal except for mild portal tract inflammation, although a true capsule was not present. The light brown areas of the tumour were composed of liver cells that appeared fairly normal, although rather 
larger than usual, but the normal lobular architecture was lost, and portal tracts and hepatic veins were absent. Randomly distributed throughout the tumour were small thick-walled arteries, occurring singly or in small groups, and dilated thin-walled blood vessels. There were also areas of extreme dilatation of sinusoids, with formation of blood-filled cysts (fig 1). In contrast, the morphology of the grey areas of the tumour was that of a well-differentiated hepatocellular carcinoma, the cells being basophilic and dysplastic with marked nuclear pleomorphism, and a few were undergoing mitotic division. The normal arrangement of liver cell plates was disrupted (fig 2), and tumour cells were present either singly or in small groups within a hyaline stroma. At the junctions between the two components of the tumour, which were sharply demarcated, there was a conspicuous inflammatory reaction, and in some areas there was further separation by a band of fibrous tissue, although penetration by groups of dysplastic cells had occurred.

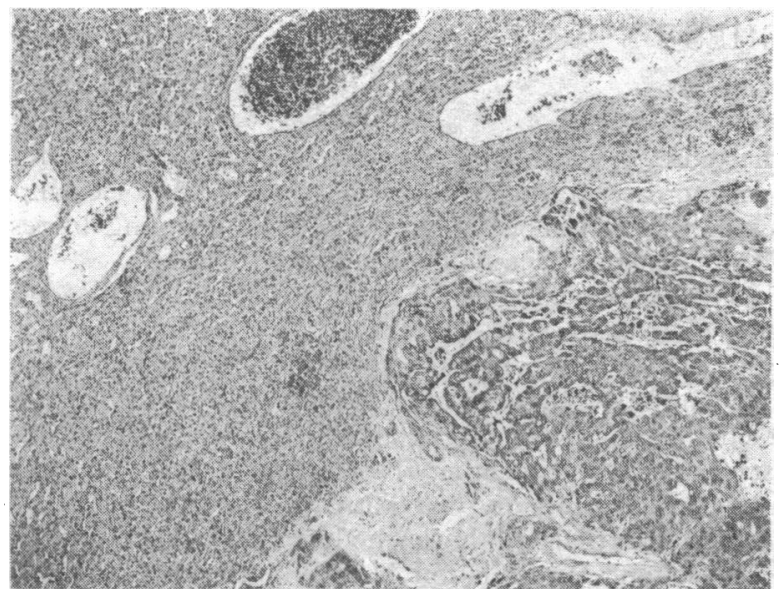

FIG 1-Well-demarcated junction between area resembling focal nodular hyperplasia (top left), containing cystic areas filled with blood, and area undergoing malignant transformation (bottom right). $(\mathrm{H}$ and $\mathrm{E} \times 82$.)

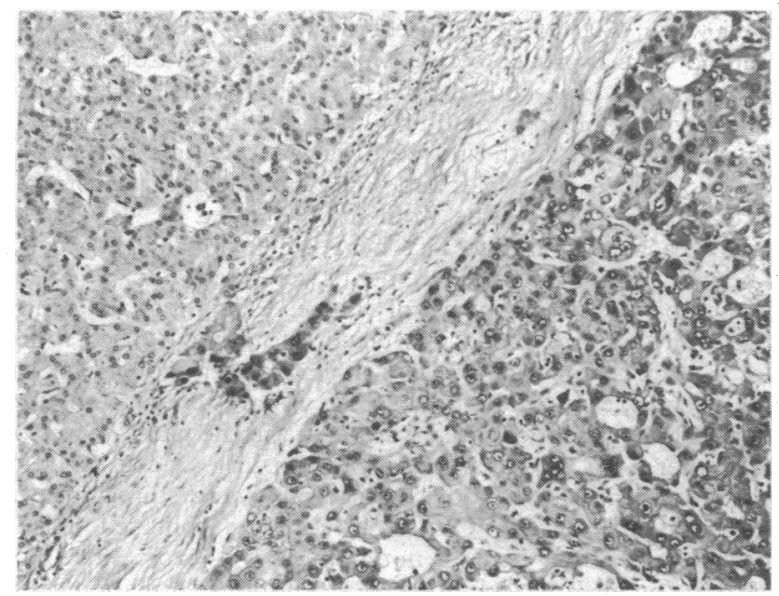

FIG 2-High-power view showing separation of two elements of tumour by fibrous band, which has been invaded by tumour cells. $(\mathrm{H}$ and $\mathrm{E} \times 136$.)

\section{Discussion}

The nomenclature of hepatic tumours associated with oral contraceptives is confused, with apparently similar histological changes being variously described as adenomas, ${ }^{1-5}>9-11$ hamartomas, ${ }^{6}$ or focal nodular hyperplasia. ${ }^{8}$ According to Edmondson's description, ${ }^{22}$ our findings would best be described as focal nodular hyperplasia, the tumour being lobulated with a central fibrous stroma and lacking a true capsule. The presence of arterial wall hypertrophy is another feature characteristic of this condition, and this too was present in our case. On the other hand, there were features that would fit better the description of benign hepatic adenoma. The liver cells were often larger than normal, and, as is characteristic of adenomas, no portal tracts, bile ducts, or central veins could be discovered within the tumour mass. In the one other patient we have seen with a hepatic tumour associated with oral contraception the mass was far more vascular than that described here and had the features of a benign hepatic adenoma. This was a 41-year-old woman who had been taking Gynovlar 21 (norethisterone acetate $3 \mathrm{mg}$, ethinyloestradiol $50 \mu \mathrm{g}$ ) for nine years and presented with haemoperitoneum from spontaneous rupture of the neoplasm, which was subsequently removed by partial left hepatectomy. Overall, therefore, these focal proliferations of hepatocytes associated with blood-filled cysts, which have been described only in patients taking oral contraceptives, cannot be classified into any existing diagnostic category.

The blood-filled cysts in these tumours bear a superficial resemblance to peliosis hepatis. It is unlikely however that they are identical with the classical lesion as described by Yanoff and Rawson ${ }^{13}$ in association with tuberculosis and other systemic disorders, for in these disorders spontaneous rupture is not a feature, and disease of the liver is diffuse rather than focal. Post-mortem radiological studies in one case of oral contraceptive-associated tumour ${ }^{11}$ showed that the blood-filled spaces were supplied by the hepatic artery, and the high pressure within them would favour their rapid expansion and eventual rupture. The anaemia with which our patient presented was almost certainly the result of small asymptomatic bleeds into the tumour, and had diagnosis not been so prompt rupture with haemoperitoneum would most probably have occurred.

All other reports have emphasised the benign nature of the tumours, but in our case, though part of the mass showed changes similar to those previously described, a large portion showed the characteristics of a well differentiated hepatocellular carcinoma. The potential of these "pill" tumours to undergo malignant transformation is not known,- but if it were similar to that found with cirrhosis, ${ }^{14}$ which is a form of diffuse nodular hyperplasia, an incidence of about $10 \%$ would be expected. Statistically, therefore, only one case of hepatocellular carcinoma would be expected among the 27 cases so far reported. In addition, many of these patients presented with bleeding, which may have led to resection or death before malignant change could have had time to occur.

Some overlap between these tumours and the malignant hepatomas reported in patients treated with anabolic steroids ${ }^{15}$ is also to be expected. Like the synthetic progestagens used in oral contraceptives anabolic steroids are C17-substituted 19nor-steroids, but whether oral contraceptives are carcinogenic in the doses administered to humans remains to be established. Chronic administration of oral contraceptive steroids to rats and mice did not produce an increased incidence of hepatic tumours unless over 200 times the human contraceptive dose was given. ${ }^{16}$ Nevertheless, this effect, which was dose related, requires further investigation. The patient who had the first reported multifocal tumour associated with oral contraception had been taking four times the normal contraceptive dose to control intractable uterine bleeding.

These cases of hepatic tumours must be considered in relation to the millions of women throughout the world who are taking oral contraceptives. Now that the clinical association with tumour formation has been described, however, more cases are likely to be described. The public is going to demand a proper assessment of the frequency of these tumours, and a central registry to which clinical and pathological data could be reported would be of considerable help, both for this purpose and in determining the nature of the tumours.

We thank Mr J L Dawson, who so expertly removed the tumour, and Miss Fabienne Kuhn, who prepared all the material for histological examination. 


\section{References}

1 Baum, J K, et al, Lancet, 1973, 2, 926.

2 Constostavlos, D L, Lancet, 1973, 2, 1200

${ }^{3}$ Knapp, W A, and Reubner, B H, Lancet, 1974, 1, 270.

${ }^{4}$ Kelso, D R, Lancet, 1974, 1, 315.

${ }^{5}$ Horvath, E, Kovacs, K, and Ross, R C, Digestion, 1972, 7, 74

6 O'Sullivan, J P, and Wilding, R P, British Medical fournal, 1974, 3, 7

7 Tountas, C, Paraskevas, G, and Deligeorgi, H, Lancet, 1974, 3, 1351.

${ }^{8}$ Mays, E T, Christopherson, W M, and Barrows, G H, American fournal of Clinical Pathology, 1974, 61, 735.

${ }^{9}$ Berg, J W, et al, Lancet, 1974, 2, 349.
${ }^{10}$ Model, D G, Fox, J A, and Jones, R W, Lancet, 1975, 1, 865.

11 Clinicopathological Conference, British Medical fournal, 1975, 3, 209.

12 Edmondson, H A, Tumours of the Liver and Intrahepatic Bile Ducts, Fascicle 25, p 18. Washington, DC, Armed Forces Institute of Pathology, 1958.

13 Yanoff, M, and Rawson, A J, Archives of Pathology, 1964, 77, 159.

${ }^{14}$ McSween, R N M, and Scott, A R, Fournal of Clinical Pathology, 1973, 26, 936 .

15 Lancet, 1973, 2, 1481.

${ }^{16}$ Committee on Safety of Medicines, Carcinogenicity Tests of Oral Contraceptives. London, HMSO, 1972.

\title{
Mastalgia and total body water
}

\author{
P E PREECE, A R RICHARDS, G M OWEN, L E HUGHES
}

British Medical fournal, 1975, 4, 498-500

\section{Summary}

Total body water (TBW) was measured early and late in a menstrual cycle in 56 women, 39 of whom had breast pain. The remainder were asymptomatic controls. Most women did not conform to the traditional view that there is a premenstrual increase in TBW. In some TBW decreased, while in others there was no change from the early cycle measurement. No TBW pattern correlated with any syndromes of breast pain or with any psychoneurotic profile.

\section{Introduction}

Mastalgia causes distress, particularly since the patient often assumes that it is associated with cancer. Sleeplessness and irritability are often ascribed to it, and surgeons may be asked to provide treatment. At the Cardiff breast clinic, some 50 new patients are seen every month, and in about five of these breast pain is the sole complaint. Many clinicians think of mastalgia as part of the premenstrual syndrome, but accounts of the syndrome, although they describe the sensations of breast distension, do not highlight breast pain as a major component. ${ }^{1}$ Dysmenorrhoea has been distinguished as a different clinical entity from the premenstrual syndrome. ${ }^{2}$ Other symptoms of the premenstrual syndrome are rarely present in premenopausal women presenting with mastalgia, yet $30 \%$ of our patients complain of dysmenorrhoea. Mastalgia has been defined as premenstrual breast pain associated with breast nodularity severe enough to demand active treatment, ${ }^{3}$ but we have seen patients in whom the symptom occurs other than premenstrually and even after the menopause.

While weight and water fluctuations during a menstrual cycle occur in women with and without premenstrual symptoms, these increases are not invariably associated with the premenstruum. ${ }^{4}$;

\footnotetext{
University Department of Surgery, Welsh National School of Medicine, Cardiff CF4 4XN

P E PREECE, FRCS, FRCSED, lecturer

L E HUGHES, FRCS, FRACS, professor of surgery

Department of Medical Physics, University Hospital of Wales, Cardiff

A R RICHARDS, MSC, physicist

G M OWEN, MSC, FINSTP, physicist
}

Furthermore, cyclical symptoms are not necessarily correlated with an increase in total body water (TBW). ${ }^{6}$ For example, a decrease in TBW has been reported as accompanying depression found premenstrually and at other times.

We have tried to clarify the role of body water in the aetiology of cyclical mastalgia by comparing body weights and TBW volumes during one menstrual cycle in patients with mastalgia and in symptom-free age-matched controls. We set out to show what changes in body weight and TBW occurred during the menstrual cycle and whether these changes were the same for patients and controls and for patients whose symptoms were always premenstrual and those who had mastalgia at other times. We also sought a correlation between mastalgia and cyclical changes in weight or water and any psychoneurotic traits, as shown by a questionnaire.

\section{Methods}

Informed consent was obtained from patients and controls. Tritiated water $(200 \mu \mathrm{Ci})$ was used to measure $\mathrm{TBW}$, and the dose and method were approved by the Medical Research Council Isotopes Advisory Panel. Whole-body irradiation with this dose was 22 mrads, and tissue irradiation amounted to 40 mrads. ${ }^{9}$ Body weight and TBW were measured on the 5th and 25th days of a single cycle in those women who had 28-day cycles and on equivalent days in women with longer or shorter cycles. The women were asked to wear the same clothes for each visit and to fast between $9 \mathrm{am}$ and 12 noon, the times between which the measurements were made.

The method was based on that of Haxhe. " " Height and weight were measured, and $5 \mathrm{ml}$ of blood was taken into a heparinised tube and used as a background reference. Tritiated water $(200 \mu \mathrm{Ci})$ (Radiochemical Centre, catalogue number TRS 1P) was drunk from a phial, followed with $50 \mathrm{ml}$ of deionised water to wash the phial. Three hours later a further $5-\mathrm{ml}$ blood sample was taken into a heparinised tube. If not counted immediately plasma samples were stored in airtight plastic containers at $-40 \mathrm{C}$. Urine was not collected since the specific activity of body water is not altered by its excretion. ${ }^{11}$ Counting was done on an Intertechnique SL-30 liquid scintillation counter; $0.3-\mathrm{ml}$ plasma samples were measured in pairs together with a pair of samples to which had been added an internal standard to determine the efficiency of counting. Results were obtained on punched paper tape and processed by an Intertechnique Multi-8 computer. Values for the TBW and standard deviations of the counting error were obtained.

Clinical information was documented on a proforma by a consultant surgeon on the first two occasions the patient was seen. Controls were not examined, but a history proforma was completed. The 48 -item Middlesex Hospital questionnaire was used to assess psychoneurosis. ${ }^{12}$ The forms were filled in at home, without help, and the scoring was carried out by one of us (PEP). The scores obtained were evaluated by comparison with specific groups. ${ }^{13}$ Statistical analysis was performed by Sumlock 340 Statistician to compare control and patient values by means of Student's $t$ test. 